\title{
BIODEGRADABLE PLASTICS FRAGMENTATION IN SOIL AND WATER: LESSONS LEARNT AND COMPARATIVE ASSESSMENT WITH HYDRO-BIODEGRADABLES
}

\author{
SULTAN MAJED AL-SALEM \\ Environment and Life Sciences Research Centre, Kuwait Institute for Scientific Research, Kuwait
}

\begin{abstract}
In the current climate, there is a surge of controversy surrounding the topic of plastics. Undeniably and unavoidably, plastic has become a crucial part of this generation. However, the inappropriate disposal of plastic waste, as well as the increase in consumption, provokes serious environmental issues. The rising environmental awareness on a global scale has imposed considerable pressure for associated authorities to take actions. This includes the research into alternative options to conventional plastics which is latched on to a negative reputation. Nevertheless, the greenness of these so called environmentally friendly alternatives is often questionable. Since April 2015, the European Parliament and the Council established Directive (EU) 2015/720, has amended Directive 94/62/EC with regards to reducing the consumption of lightweight plastic carrier bags. Subsequently, the directive aims to reduce the level of littering of these bags which accumulates in the environment where more plastic-related problems (i.e. marine pollution) aggravates. In this work, a comprehensive fragmentation analysis was conducted on biodegradable plastic bags claimed to be green and environmentally friendly for arid environments. Various biodegradable compounds were tested and verified for such claims in this work. The first stage of the experimental campaign involved conditioning the samples under UV (to trigger decomposition) until fragmentation is reached; and record the Fourier Transform Infrared Spectroscopy spectra every 72 hours. The use of a reference material for comparative analysis was also applied, and the material was chosen to be polylactic acid. Furthermore, fragmentation in water was conducted where the plastic is conditioned in an aqueous environment. Lastly, the samples were mixed with sand and mud, and weathering induced fragmentation was continued. Infrared analysis was undertaken and the rate of biodegradation was determined. The above analysis was also used to draw lessons learnt from this exercise for oxo and hydro-biodegradables; and how to best utilize them as a waste management mitigation strategy.

Keywords: biodegradation, polyester, starch, polymer waste, waste management.
\end{abstract}

\section{INTRODUCTION}

Landfilling is considered to be the most common waste disposal method namely for municipal solid waste (MSW). With all the advances in technology available to it, the United States (US) generates some 267 million tonnes of MSW on an annual basis amounting to $4.5 \mathrm{lb}$ per person per day [1]. The total of 52\% (139 million tonnes) is also landfilled on an annual basis. A major element of which are plastics. Plastic solid waste (PSW) comprises $12 \%$ of the global MSW composition [2]. Some reports show, namely for developing countries, that PSW comprise over 18\% of MSW that is landfilled [3], [4]. Problematically, PSW is lightweight and inert on a chemical level. These might be some of its advantages when production and conversion takes place, however, are a major obstacle to landfill authorities when PSW is disposed of. Both film and rigid PSW also occupy valuable landfill space and has been related to various environmental stressors in the past [5]. A prime solution as of late is biodegradable plastics that have been popularised recently due to various advantages namely weight and size reduction of material with exposure to humidity and UV light [6]-[9]. Biodegradation refers to a degradation mechanism which 
involves the breakdown of organic chemical compounds via biological activity into more environmentally acceptable substances such as water, $\mathrm{CO}_{2}$, new biomass or mineral salts of any present elements known as mineralisation. More specifically, the biological activity may be enzymatic, microbial and/or fungal activity. Furthermore, this process may take place in an oxygen-rich environment (aerobic condition) or in the absence of oxygen (anaerobic condition). In order for a plastic to be certified as a "biodegradable plastic", it must oblige to three specified parameters: (1) degree of degradation, (2) timespan of degradation, and (3) surrounding conditions of degradation. In addition, the certification bodies that are authorised to award such certifications, must follow standardised test methods (maybe more than one) to ensure the material satisfies all the appropriate specifications. It must be noted that all compostable materials are biodegradable, but a product that is labelled as biodegradable is not necessarily compostable. This statement is to clarify any misconception and prevent public from misleading information. The reader is referred to Al-Salem et al. [7]-[9] for the recent advances in standardization within the State of Kuwait for oxo-biodegradable plastics.

Biodegradable plastics can be classified into two main types, oxo-biodegradables and hydro-biodegradables. Oxo-degradable plastics are additivated with inorganic metal salts or pro-degradants. Whereas, a smaller portion of the group uses organic additives which are claimed to be consumed by micro-organisms. During the consumption process, the microorganisms excrete acidic and enzymic substances which aid the breakdown of plastic material. Subsequently, the broken down and smaller pieces of plastic can be consumed by microbes with ease. This group is known as the "enzyme-mediated degradable plastics" [10]. On the other hand, hydro-biodegradables are a class of plastics with a portion of a renewable (naturally biobased) component such as rice or potato starch additives. The US guideline ASTM D6954 was once the sole available guide on testing oxo-degradable plastics for many years. As of 2009, increasingly number of guides and standards were developed throughout Europe and Middle East. Moreover, it must be acknowledged that guidelines and standards are separate entities. To elaborate, guidelines prescribe the procedures of different test methods, in which the ASTM D 6954 and BS 8472 are comparable in this case. However, standards consist of a higher level of details and quality which includes pass/fail criteria alongside the timescales in which the criteria must be satisfied by. For example, UAE/S 5009 and SPCR 141 are qualified as standards. In summary, the claim of conformity is not possible when testing complies solely to guidelines but without standards. According to a study published by the European Commission in 2018 [11], evidence shows suggests that oxo-degradable plastic is not suitable for any form of anaerobic digestion or composting. Thus, it will not fulfil the existing standards for packaging recoverable through composting within the EU. The OxoBiodegradable Plastic Association (OPA) stated that oxo-degradable plastics are not marketed for composting [12]. Dissimilarly to biodegradable plastics, despite some claims, oxo-degradable plastics are not compostable and will not degrade in landfill conditions. This is agreed upon by a large share of the industry. Furthermore, oxo-degradable plastics do not fulfil the specified requirements of (industrial and domestic) composting laid out by many accredited standards. This means that this type of material is not appropriate for compostable food service applications as an example which alternatively is a major share of solid waste landfilled.

In 2015, France was the first country to take concrete action to prohibit the production, distribution, sale, provision and utilisation of packaging or bags made either partially or completely of oxo-degradable plastics [13]. Recently, Spain became the second country to implement a similar law [14]. It is highly likely that other (EU) countries will follow suit as 
well. At the beginning of 2018, the European Commission (EC) has issued a statement that, the commission will take actions to "restrict the use" of oxo-degradable plastic across the EU member states. This statement was motivated by the concern that oxo-degradable plastics fragments into microplastic (MP) which subsequently pollute fauna and flora. This statement was published in the EC's plastics strategy on 16 Jan. 2018 [15]. A summary of standardisation and standards used in oxo-biodegradation is available elsewhere for the reader's consideration on the subject matter [8]. The commission further adds that there is no evidence to prove that oxo-degradable plastics offer any advantages over conventional plastics (which can be recycled).

Furthermore, the commission has revealed plans to regulate that all plastic packaging to be recyclable by 2030 . The statistics is manly influenced by policies and legislations which are dependent on the country and regions. For instance, countries such as Pakistan, UAE and Yemen have legislations in favour of oxo-degradable plastic. Thereby, even for European based additive manufacturers, the main supply demands come from other regions. The estimation is determined on the basis of aggregated tonnage data obtained from European and non-European manufacturers. Nevertheless, from the available data, the Middle East and Central and South America were the two largest markets for pro-oxidant additives, each dominating around a third of the market. Recently efforts have taken place within the State of Kuwait to standardise the use of such materials with the aim of reducing waste accumulation [16]-[19]. Therefore, and as a continuing effort led by the Kuwait Institute for Scientific Research (KISR), standardisation of the use of hydro-biodegradable plastics in context of past effort with oxo-biodegradables is initiated. This communication represents the cornerstone of the aforementioned project where the experiences gathered from past efforts on oxo-biodegradables are compared with those from our ongoing research works on hydro-biodegradable polymer blends. The behaviour of the prior is investigated in various media to mimic their behaviour in various environmental sinks.

\section{EXPERIMENTAL}

The samples acquired were presumed to be environmentally friendly and biodegradable, which were secured from various sources within the state. The samples were cut into standard testing dimension specimens accepted by international protocols for thin plastic film characterization as described previously. For further details on types of the three bags which will termed Types 1 (yellow), 2 (blue), and 3 (white) herein, the readers are referred to our earlier work cited in this communication [7]-[9] including metal/additive content and experimental campaign for field testing. For the sake of comparison, plastic grades were purchased in the form of a standard grade of polylactide acid (PLA) which is a natural biodegradable material (Ingeo ${ }^{\mathrm{TM}}$ Biopolymer 4043D), as well as, a standard type of polyethylene (PE) bag used in an internationally recognised commercial outlet. Weathering in accelerated mode was conducted using stripes from the three different bags placed in a UV weatherometer machine from Q-SUN (Q-SUN Xe-3 Xenon Arc Test Chamber). The Q-SUN Xe-3 xenon arc chamber reproduces the damage caused by full-spectrum sunlight and rain. In a few days or weeks, the Q-SUN tester can reproduce the damage that occurs over months or years outdoors. The Q-SUN Xe-3 tester is a full-featured lightfastness, colourfastness, and photostability chamber. For conditioning the principles of ISO $4892-$ 1/2016 - Part 1; were followed. To simulate the conditions in the Middle East and at the same time to speed up the fragmentation process we have used the following UV weathering parameters: Weatherometer: Eriskay, X3HS, T178, Filters: Daylight Q Filters, T211-Irradiance (nm): 340 (T169) - Power $\left(\mathrm{Wm}^{-2}\right): 0.35$ - Chamber Temperature $\left({ }^{\circ} \mathrm{C}\right): 43$ - Black Panel Temperature $\left({ }^{\circ} \mathrm{C}\right): 63$ - Relative Humidity $(\% \mathrm{RH})$ : N/A - Light Cycle only - 
No spray cycles - Calibration Radiometer: CR20/340-D (Daylight filters) M142R. Specimens from the Types 1, 2, 3, commercial bag and PLA samples were placed for UV weathering and tested every 48 hours till 576 hours for carbonyl growth via the FTIR and every 100 hours till 200 hours for tensile performance. For Reference, 210 hours of weathering corresponds to approximately 2 to 3 months in real exposure time in sun. An IS10 Thermo-Nicolet FTIR machine equipped with an ATR attachment was used for the analysis of the bags. Sample were tested without any prior sample preparations. 32 scans per specimen were taken for better accuracy. For the carbonyl-oxidation analysis the weathered samples were analysed with the FTIR IS10. The peak areas from the 2,800 to $2,870 \mathrm{~cm}^{-1}$ and from the 1,600 to 1,850 regions were used for the carbonyl index (CI). An example of the analysis is shown in Fig. 1. See FTIR Index section for further details. In addition to the carbonyl, vinyl index was also calculated using the IR peak at $909 \mathrm{~cm}^{-1}$ and the reference peak 2,800 to $2,870 \mathrm{~cm}^{-1}$ (Figs 1 and 2).

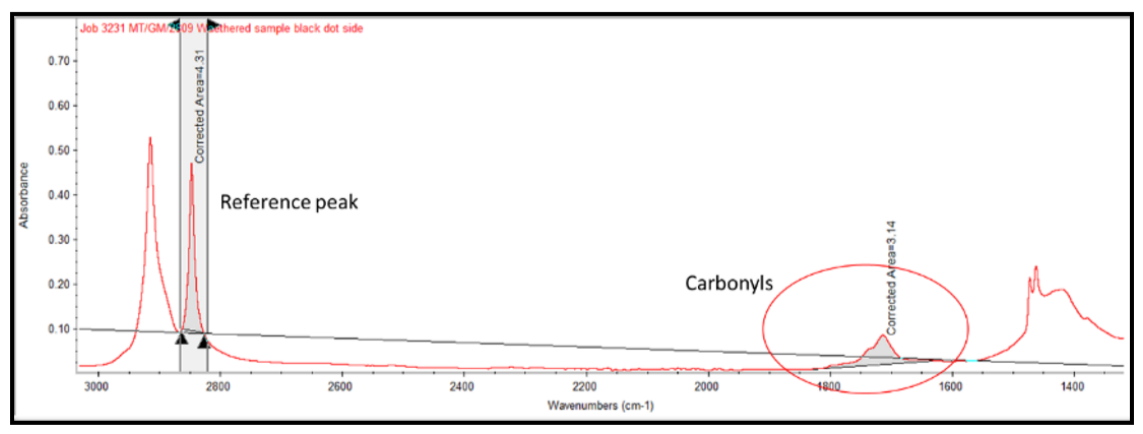

Figure 1: FTIR Spectrum highlighting the carbonyl formation due to degradation/ reference peak used in the analysis.

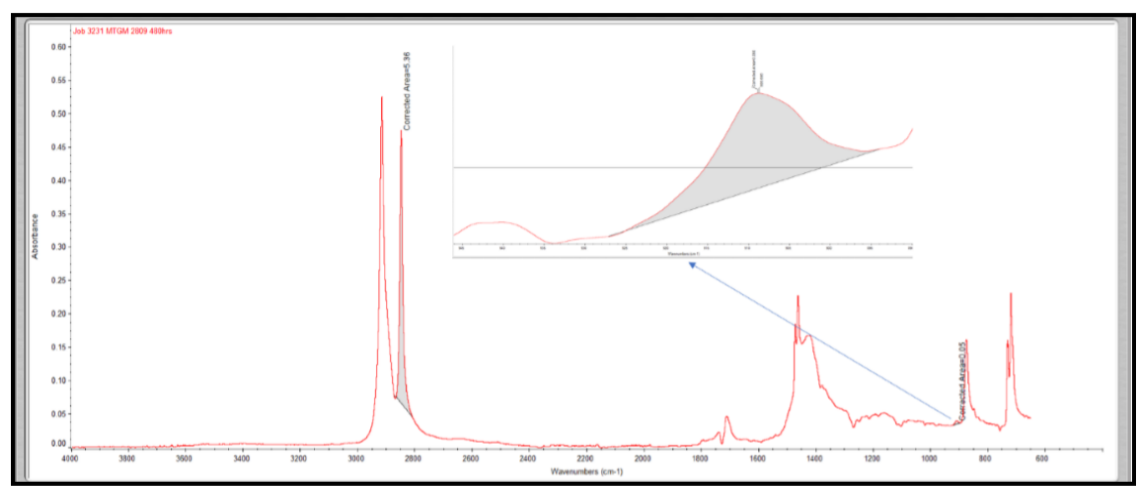

Figure 2: FTIR spectrum highlighting the carbonyl formation due to degradation.

Ageing in water took place by placing samples from the three different bags in glass bottles of water. The bottles with the samples were then placed in an air oven set at $65^{\circ} \mathrm{C}$ for ageing. Samples were inserted for testing the 22 Mar. 2018 and removed after 2 months. 


\section{RESULTS AND DISCUSSION}

Specimens cut out from the commercial bags were placed in accelerated UV weathering chambers to assess the initiation and progression of the degradation process. The samples placed in the UV chamber were visually inspected on a periodical basis and tested under the FTIR for carbonyl growth, i.e. oxidation. In addition, the mechanical properties of the bags were determined upon UV exposure [17]. In the meantime, all samples were placed in water and at elevated temperature to investigate whether degradation is triggered in dark humid environments. Strips of the all the three samples were placed in water bottles at $65^{\circ} \mathrm{C}$ for ageing. A PLA sample along with a non-biodegradable bag form the commercial PE bag (Type 4) were also placed in water for testing. After almost 2 months of conditioning, none of the three types of bags showed evidence of degradation, including the supermarket bag (Type 4). But, the PLA film after approximately 20 days of conditioning became very brittle with a sugary texture when handled, indicating that the sample was degrading. Preliminary UV weathering tests revealed that the Type 2 blue sample started to fragment significantly after 65 hours, while the Type 1 and 3 bags were becoming brittle at approximately 200 hours. 200 hours of weathering corresponds to roughly 2 to 3 months in real exposure time in sun. Fig. 3 below shows the specimens after exposure to UV. This is a direct indication that the additives used to break down the PE bags are oxo-biodegradable and are activated with UV light [9] (Fig. 3). Composition of each bag is given elsewhere [7]-[9].

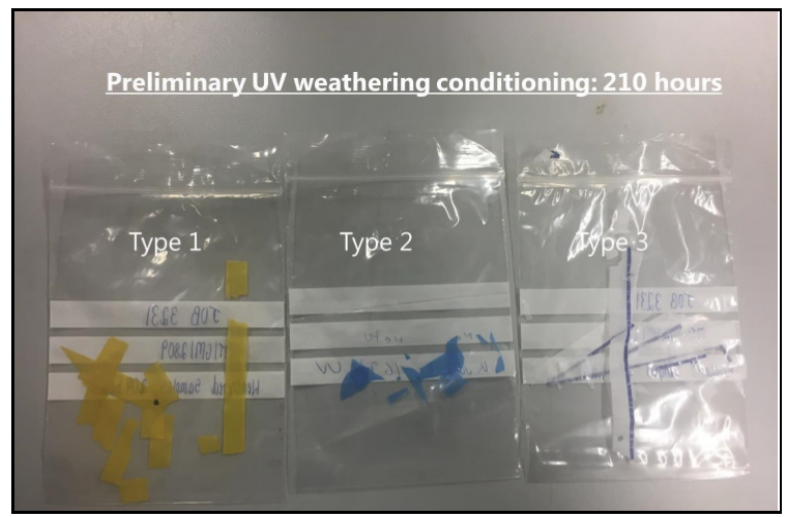

Figure 3: Preliminary UV weathering resistance tests in the three types of bags (210 hours).

Upon completion of the preliminary tests, more samples were placed in the UV chamber for in depth comparison of the oxidation and degradation processes. Specimens were removed from the chamber for infrared testing every 48 hours. From the collected FTIR spectra, the carbonyl indexes were determined and plotted against the time of UV exposure for each sample. Table 1 below shows the carbonyl index data along with the peak area calculations from the FTIR spectra. Fig. 4 shows the relation between carbonyl index and weathering time in hours for all three types of bags along with the reference commercialinternational supermarket bag up to 384 hours. The linear trend lines are also shown. The slopes (gradient) are also highlighted in Fig. 4 with the Type 2 sample showing the highest slope and the Type 3 and commercial bag (Type 4) the lowest. In addition, Fig. 5 presents 
the graphs for all specimens across the full accelerated UV weathering conditioning. From the graphs we found that Type 2, blue bag showed faster growth of carbonyls on the surface and subsequently faster oxidation compared to the rest of the samples. The slope (gradient) of the blue sample was almost double than the slope of the yellow (Type 1) sample and much higher than the rest samples. Type 1, yellow bag showed slightly faster and higher oxidation than the Type 3 bag and less than the Type 1. Finally, according to the graph in Fig. 4, the Type 3 white bag showed similar oxidation behaviour with the commercial PE non-biodegradable bag. According to the graphs in Fig. 5, the best fitting for the Carbonyl growth behaviour is the polynomial, as a result the oxidation process does not have a linear relation with the weathering time.

The FTIR spectra focusing on the region where the carbonyl growth takes place at approximately $1,720 \mathrm{~cm}^{-1}$ are shown in Fig. 5. Near the carbonyl peak, an additional peak at around $1,800 \mathrm{~cm}^{-1}$ was evident in all samples including the reference commercial PE bag. According to the IR spectra the size of this additional peak was reduced with increasing the weathering exposure and the carbonyl peak was growing. It is very likely that these additional peaks are associated with the presence of UV absorbers or
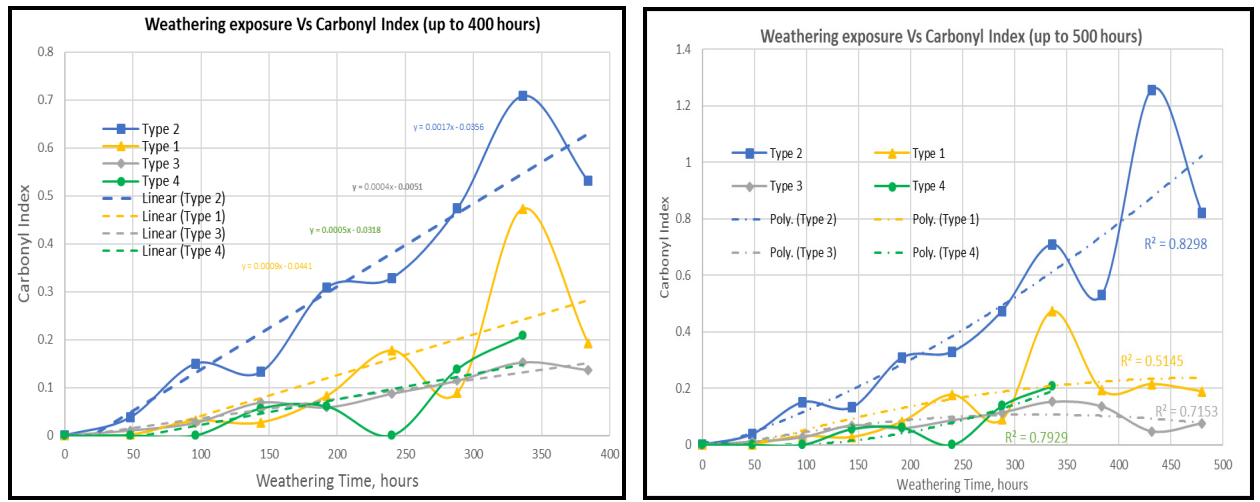

Figure 4: (Left) UV Weathering exposure vs. carbonyl index for all three types of bags plus the type 4 (commercial bag) reference PE bag, focusing on the up to 400 hours of weathering area. The linear fitting curves are also shown along with the slope gradient, (right) weathering exposure vs. carbonyl index for all three types of bags plus the reference pe bag, focusing on the up to 500 hours of weathering area. The polynomial fitting curves are also shown along with the square root of fitting.

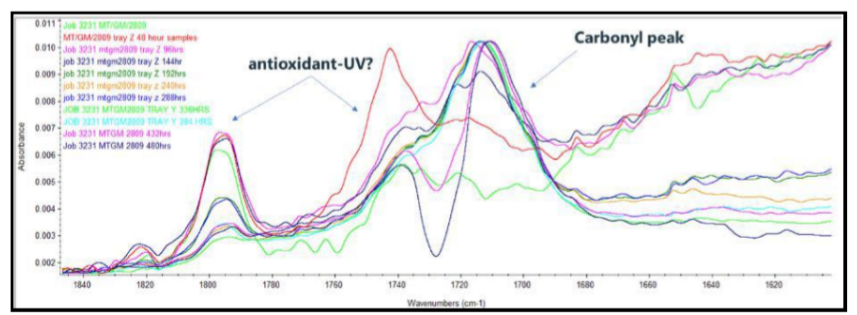

Figure 5: Carbonyl growth showing IR spectra for Type 1. 


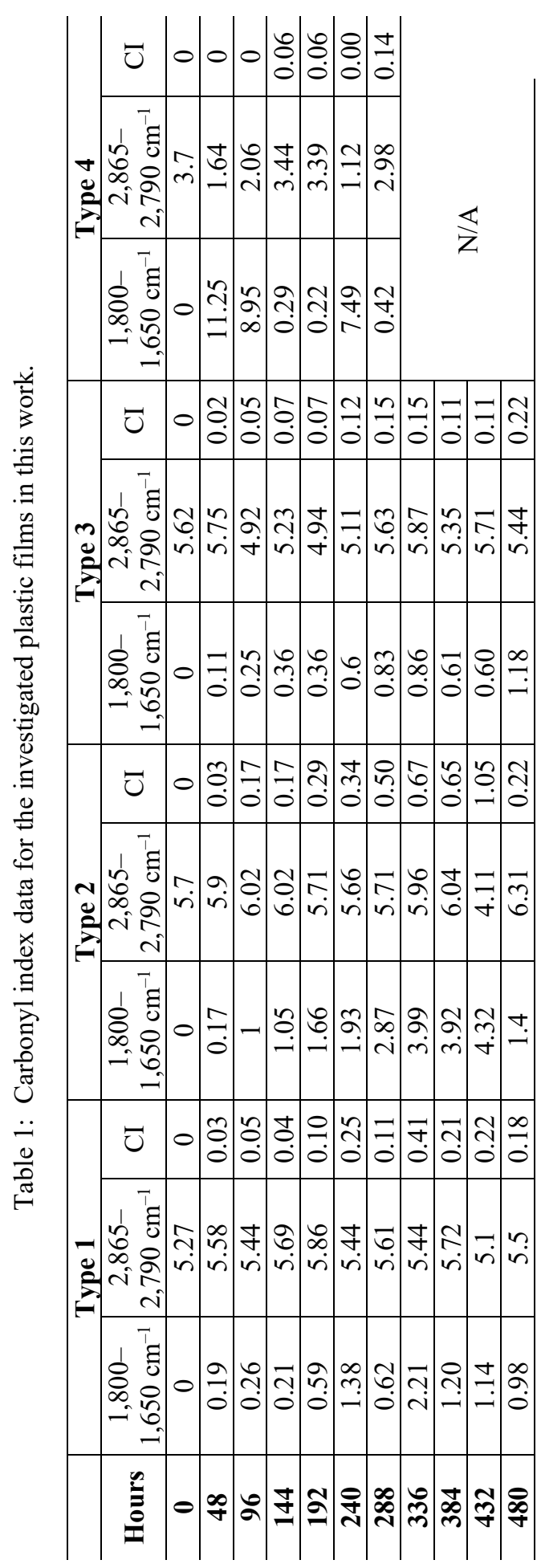


antioxidants. But, as shown in Fig. 5, the Type 2, blue bag did not show a similar UV/antioxidant peak like the rest of the samples. It did show though a small peak at $1,660 \mathrm{~cm}^{-1}$ which could be related to antioxidants, but further analysis is required to support this argument. In any case, lack of antioxidants and or UV absorbers could be the reason why the Type 2, blue sample exhibited faster and bigger degradation-fragmentation than the rest of the samples. Furthermore, the vinyl index has been also calculated and plotted against the UV weathering hours. Fig. 6 presents the Vinyl index vs. UV weathering graph for the three types of bags including the reference commercial PE bag. From the graph it became evident that the reference bag from commercial PE bag (nonbiodegradable) yielded much higher vinyl index during weathering exposure compared with the three types of bags. Also, the vinyl index of the Type 3 (white) bag did not change significantly during the UV weathering exposure.

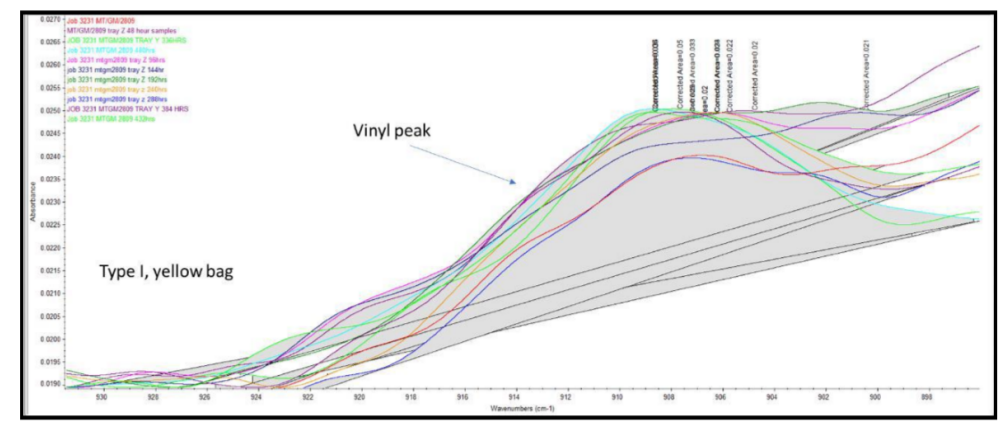

Figure 6: Type 1: Yellow sample IR spectra focusing on the vinyl growth.

Visual inspection of the weathered samples showed that the Type 1 yellow bag started fragmenting after approximately 288 hours, while the Type 2 blue sample after 192 hours. The Type 3 white bag did not show evidence of fragmentation before 400 hours. The reference clear bag from commercial PE bag showed traces of decomposition after 190 hours of weathering and PE specimens were blown away inside the UV chamber. The composition of each bag is given elsewhere [7]-[9].

The degradation process, simulating landfill conditions, will also be assessed and discussed in this section. The reference Type 4 was used for comparative assessment. The fragmented specimens from the analysis shown before will be mixed in wet sand and wet mud, compressed in individual boxes and was placed in the UV weatherometer for further conditioning. A wet cycle was added in the weathering program to keep the sand and mud samples wet in order to apply more "pressure" in the fragmented plastic pieces and accelerate the degradation process. Specimens were assessed periodically for degradation. For further UV weathering, the fragmented sample pieces were mixed with wet sand and wet mud and placed in rectangular plastic boxes of the same size. The sample preparation was kept consistent in order to apply packing, stacking pressure and environmental conditions similar to an actual landfill. Fig. 7 presents the filled boxes with all the samples mixed in sand. Both the boxes with the wet sand and the wet mud were then placed in a state-of-the-art accelerated UV (Xenon-arc) environmental chamber (Fig. 7). The environmental conditions were as per the following: $\mathrm{RH}$ : $60 \%$, Temperature: $65^{\circ} \mathrm{C}$ using a daylight program. Sand and mud properties are depicted in Al-Salem et al. [19]. 


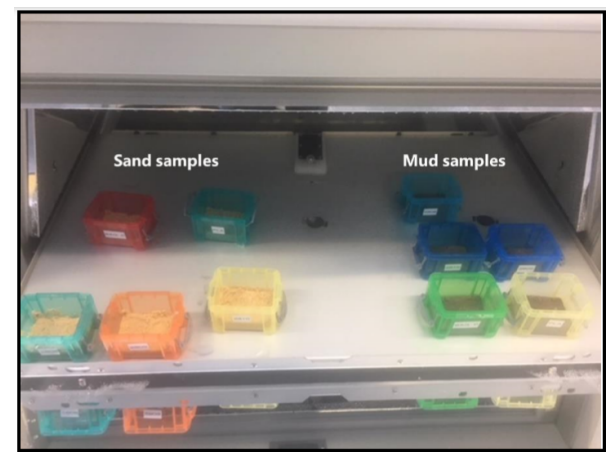

Figure 7: Samples mixed in mud and sand placed in the UV weathering chamber for further conditioning.

In total, the samples were exposed under UV for 1,200 hours which is more than a year in real time of sun exposure. The samples were mixed manually approximately every 72 hours. Every 200 hours (or 100 hours occasionally) of UV weathering a small amount of mixed sand and mud was removed from the boxes for degradation analysis. The degradation analysis was carried out visually, with GCMS and with FTIR, carbonyls. The presence of relatively large fragments in the mud and mud made the GCMS method very difficult to get meaningful results. The readers are referred to Al-Salem et al. [19] for further details. Following the completion of the UV weathering cycle, the sand and mud boxes were visually inspected for any remains of PE fragments. Fig. 8 shows an example of the sand and mud boxes exposed in UV for Type 1. The red circles in Fig. 8 highlight the presence of plastic fragments at all sand and mud samples. This is a clear indication that none of the bags were fully decomposed even after approximately 1 year of exposure in daylight (1,200 hours under UV). However, we have noticed visually the presence of much smaller polymer fragments in the mud samples.

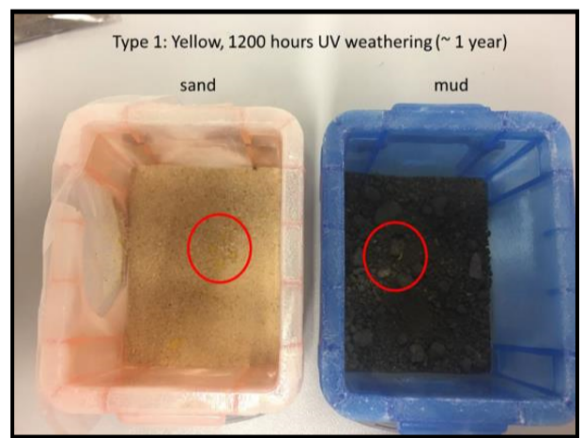

Figure 8: Type 1: Yellow bags in sand and mud, conditioned under UV for 1,200 hours.

The fragmented polymer pieces left in the sand and mud boxes after UV weathering, were collected and analysed with FTIR in order to assess the levels of carbonyls. The analysis was carried out and continued with the same method as previously mentioned. From the analysis, it is concluded that the Type 2 blue sample reached the maximum of 
oxidation between 400 and 500 hours i.e. no further oxidation-degradation took place in the sand box. In regards to the Type 1 and Type 3 samples, these have shown further degradation-oxidation during conditioning in the sand box. The fragments from the PE bag yielded higher carbonyl growth-oxidation in line with the Type 1 and Type 3 bags, with a slight decrease after 1100 hours. Finally, the oxidation behaviour of all the samples conditioned in sand and mud under UV was also studied. Fig. 9 shows the carbonyl index at 1200 hours of accelerated UV weathering vs. the mud and sand.

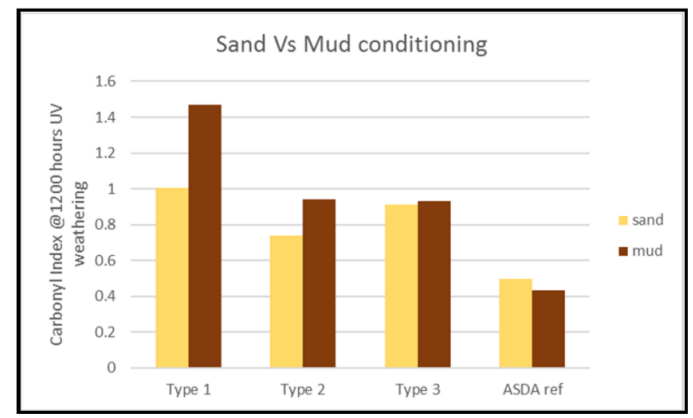

Figure 9: Carbonyl index at 1,200 hours of UV weathering of the samples conditioned in sand and mud.

From Fig. 9, it becomes evident the biodegradable samples conditioned in mud showed higher oxidation compared with the samples mixed with sand. This is not the case for Type 4. These results are in line with the visual observations undertaken and presented in previous sections. Breslin [20] studied the extent of deterioration of starch-plastic composites over a 2-year period for samples buried in a landfill. The limited degradation observed was attributed to the ineffectiveness of the pro-oxidant additive to catalyse the thermal oxidation of the plastic component of the starch-plastic composite under the environmental conditions present within the landfill. Song et al. [21] performed UV accelerated weathering followed by mechanical abrasion (MA) on various plastics to simulate the mechanism of microplastic evolution in marine environments. The rate of fragmentation by UV exposure duration increased more for PP than PE. These findings also support our current work, where it is suspected that the content of plasticizers, pro-oxidants and pro-degradants, will impact the fate of the biodegradable plastic exposed to open environments. It is also essential to keep track of potential chemicals that might pollute soils that plastics deteriorate in [22]. Viera et al. [23] assessed the impact of false claims by manufacturers in support of certain products which are marketed as biodegradables. Recently, Abed et al. [24] showed that oxo-biodegradable polymers are susceptible to biofouling. The formation of hydroxyl groups and carbonyl bonds, by Fourier-transform infrared spectroscopy (FTIR), suggests chemical degradation of the oxo-PE grade tested in the Arabian Gulf sea body.

\section{CONCLUSION AND IMPLICATIONS ON HYDRO-BIODEGRADABLES}

Accelerated UV exposure tests, revealed that all three types of bags started degrading after a certain time of conditioning. Upon 210 hours of exposure in UV, type 2 bags showed higher extent of fragmentation than the rest of the bags. 200 hours of UV exposure is approximately 2 months of exposure in UV in real conditions. From the analysis it was 
noted that Type 1 bag showed evidence of fragmentation after approximately 280 hours or 3 months in real time exposure to sun. The slope (oxidation rate) was lower than the Type 2 , blue bag and higher than the Type 3 and the reference Type 4 bag. The presence of antioxidants appeared to have slightly delayed the carbonyl growth and oxidation. After approximately 5 months of simulated exposure, the specimens showed extensive brittle behaviour and fell apart when handled with hands. When compared with the reference PE bag from Type 4, Type 1 sample showed faster growth of carbonyl but similar fragmentation process. Type 3 bag: Type 3 white bag, showed traces of fragmentation after approximately 4 months of real time exposure. The presence of antioxidants might have hindered the oxidation and fragmentation process. The tensile strength of the White bag has been dropped by $43 \%$ after 200 hours of conditioning in the UV chamber, indication that the bag has not yet been fully degraded [19]. All three types of PE bags along with the reference non-biodegradable PE bag were placed in an accelerated UV chamber in humid, high temperature and daylight conditions to assess their total decomposition behaviour. To better simulate the landfill environmental conditions all samples were mixed with wet sand and mud and placed in plastic boxes (compacted) before placed into the UV chambers. The total time of exposure under UV for all specimens was approximately 1,200 hours. This corresponds to more than 1 year of actual exposure under the daylight (approximately 15 months). Sand and mud samples with the PE films were taken out from the chamber every 200 hours for visual and infrared inspection. FTIR, revealed the further oxidation of the Type 1, Type 3 and the reference Type 4 samples. Following the full weathering cycle, a series of fragments from all samples were evident still in the mud and the sand boxes, clear indication that the samples have not been fully decomposed. Quantitatively, more fragments were evident in the sand boxes compared with the mud ones. Also, the extent of oxidation at 1200 hours of UV was great in the mud boxes for the Types 1, 2 and 3 samples compared with the oxidation in the sand. In conclusion, it became evident from the results that the PE bags (Type 1, Type 2 and Type 3) did not decompose following a prolonged exposure under UV in a high temperature humid environment and mixed with sand and mud. It is imperative to consider these findings in-light with naturally filled biodegradables with starch and other chemicals, namely hydro-biodegradables to identify the best practice in a certain region or a country.

\section{ACKNOWLEDGEMENTS}

The author would like to extend his gratitude for the Kuwait Institute for Scientific Research (KISR) for funding research project EM065K. The author would like to thank the Kuwait Foundation for the Advancement of Sciences (KFAS) for funding this scientific mission.

\section{REFERENCES}

[1] USEPA, National overview: Facts and figures on materials, wastes and recycling, 2017. www.epa.gov/facts-and-figures-about-materials-waste-and-recycling/nationaloverview-facts-and-figures-materials.

[2] Kaza, S., Yao, L., Bhada-Tata, P. \& Van Woerden, F., What a Waste 2.0: A Global Snapshot of Solid Waste Management to 2050, World Bank: Washington, DC, 2018. DOI: 10.1596/978-1-4648-1329-0.

[3] Franklin Associates Ltd., Characterization of municipal solid waste in the United States, 1960 to 2000 (Update 1988). Final report prepared for U.S. Environmental Protection Agency, Prairie Village (KS), 1990. 
[4] Al-Jarallah, R. \& Aleisa, E., A baseline study for municipal solid waste characterization for the state of Kuwait. Waste Management, 34, pp. 952-960, 2014.

[5] Briassoulis, D. \& Dejean, C., Critical review of norms and standards for biodegradable agricultural plastics, Part I. Biodegradation in soil. Journal of Polymers and the Environment, 18, pp. 384-400, 2010.

[6] Al-Salem, S.M., Influential parameters on natural weathering under harsh climatic conditions of mechanically recycled plastic film specimens. Journal of Environmental Management, 230, pp. 355-365, 2019.

[7] Al-Salem, S.M. et al., Thermal response and degressive reaction study of oxobiodegradable plastic products exposed to various degradation media. International Journal of Polymer Science, 9612813, 2019.

[8] Al-Salem, S.M., Sultan, H.H., Karam, H.J. \& Al-Dhafeeri, A.T., Determination of biodegradation rate of commercial oxo-biodegradable polyethylene film products using ASTM D 5988. Journal of Polymer Research, 26, p. 157, 2019.

[9] Al-Salem, S.M., Al-Hazza'a, A., Karam, H.J., Al-Wadi, M.H., Al-Dhafeeri, A.T. \& Al-Rowaih, A.A., Insights into the evaluation of the abiotic and biotic degradation rate of commercial pro-oxidant filled polyethylene (PE) thin films. Journal of Environmental Management, 250, 109475, 2019.

[10] New Plastics Economy Initiative of the Ellen MacArthur Foundation. https://ecostandard.org/wp-content/uploads/oxo-statement.pdf.

[11] European Commission, Final Report: Study to provide information supplementing the study on the impact of the use of "oxo degradable" plastic on the environment, 2017.

[12] Oxo-Biodegradable Plastics Association (OPA), Oxo-bio technology reduces plastic waste in the environment. www.biodeg.org/OPA $\% 20$ response $\% 20$ to $\% 20$ Ellen $\% 20$ MacArthur\%20report\%20-\%2011.1.18.pdf.

[13] Oxo Statement, New plastics economy, 2017. www.european-bioplastics.org/over150-organisations-back-call-to-ban-oxo-degradable-plastic-packaging/.

[14] Oxo-degradable plastics increasingly under fire in Europe, 2017. www.europeanbioplastics.org/oxo-degradable-plastics-increasingly-under-fire-in-europe/.

[15] Communication from the Commission to the European Parliament, the Council, the European Economic and Social Committee and the Committee of the Regions, 2018. https://ec.europa.eu/environment/circular-economy/pdf/plastics-strategy.pdf.

[16] Al-Salem, S. et al., Investigating biodegradable bags standards and properties under Kuwait's environmental conditions, volume I: Aerobic biodegradation and degressive media impact. Final Report, Project Code: EM097C, May, 2019.

[17] Al-Salem, S. et al., Investigating biodegradable bags standards and properties under Kuwait's environmental conditions, volume II: Natural and accelerated weathering studies. Final Report, Project Code: EM097C, May, 2019.

[18] Al-Salem, S. et al., Investigating biodegradable bags standards and properties under Kuwait's environmental conditions, volume III: Thermal degradation kinetics. Final Report, Project Code: EM097C, May, 2019.

[19] Al-Salem, S. et al., Investigating biodegradable bags standards and properties under Kuwait's environmental conditions, volume IV: Development of governing standards for the use of biodegradable plastic bags in the state of Kuwait. Final Report, Project Code: EM097C, May, 2019.

[20] Breslin, V.T., Degradation of starch-plastic composites in a municipal solid waste landfill. Journal of Environmental Polymer Degradation, 1(2), 1993. 
[21] Song, Y.K., Hong, S.H., Jang, M., Han, G.M., Jung, S.W. \& Shim, W.J., Combined Effects of UV exposure duration and mechanical abrasion on microplastic fragmentation by polymer type. Environ. Sci. Technol., 51, pp. 4368-4376, 2017.

[22] Tudor, V.C., Mocuta, D.N., Teodorescu, R.F. \& Smedescu, D.I., The issue of plastic and microplastic pollution in soil. Materiale Plastice, 56(3), 2019.

[23] Viera, J.S.C., Marques, M.R.C., Nazareth, M.C., Jimenez, P.C. \& Castro, I.B., On replacing single-use plastic with so-called biodegradable ones: The case with straws. Environmental Science and Policy, 106, pp. 177-181, 2020.

[24] Abed, R.M.M., Muthukrishnan, T., Al Khaburi, M., Al-Senafi, F., Munam, A. \& Mahmoud, H., Degradability and biofouling of oxo-biodegradable polyethylene in the planktonic and benthic zones of the Arabian Gulf. Marine Pollution Bulletin, 150, $110639,2020$. 